\title{
Transnational and Transdisciplinary Research Networks: Creating Learning Spaces by Transcending Boundaries for Collaboration
}

\section{Katharina Lunardon, Pier Paolo Pasqualoni and Chompoonuh K. Permpoonwiwat}

In recent literature, the concept of learning spaces has been fruitfully applied to a number of research areas. It is this concept that shall be used to describe how mutual and collective learning and innovative ideas can be facilitated within transnational and transdisciplinary networks and projects in which physical, virtual, affective and cognitive contributions of single researchers and research groups span a net of overlapping learning spaces created around a mutual research interest.

Such enterprises typically take place in a variety of spaces, and - beyond the member's workplaces - at non-places in particular. The authors provide some evidence for how a concept of learning spaces, and according theoretical frameworks, can provide added value for the purpose of identifying and reflecting on challenges typically met and opportunities unexpectedly created in the attempt to make transnational and multi-professional collaboration work. Their contribution highlights some preconditions of building trust among the researchers; means to foster and to maintain their commitment to a common research enterprise; key issues to consider when forming and expanding the network; the role and significance of communication and of shared norms.

Key words: Learning spaces, transnational collaborations, transdisciplinary research networks, group dynamics, non-places

\section{Introduction}

The first universities were institutions in which scholars and students from different cultural backgrounds joined in to form a community in its own right. Special freedoms were assigned to the community and its members to ensure they could 
concentrate on their key tasks: to pursue knowledge by joined efforts in learning, teaching and scholarly enquiry.

From a historical perspective, higher education has itself been a highly international enterprise, and it continues to be across the globe, although - in terms of locations it seems to have shifted from physical places to spaces. Such spaces, beyond merely being inhabited, constantly need to be shaped by the participants.

In the present day environment, "[i]nternationalization is an integral part of a continuous process of change in higher education; increasingly it is becoming a central motor of change. Its importance has grown along with the more general developments of globalization, offering new opportunities but also posing new challenges." (Egron-Polak \& Hudson 2014: 5) Beyond being increasingly demanded by policy-makers, research funds and key actors within higher education institutions, internationalization not only continues to be associated with broadening researcher's horizons. It also carries the promise of leading to innovation, and appears thereby to have assumed a new function. This is, however, not always straightforward to realise, and - despite being a powerful tool to collect data and building data bases - there are only few examples of international research projects that actually lead to theoretical or methodological innovation.

International cooperation is facilitated by a degree of harmonization among the educational systems and environments. Still, diversity remains the main asset for institutions to go international, particularly in the area of education. In this context, the diversity of a research group enriches the discourse by saturating on-going debates with divergent perspectives. Thus, for using diversity as an educational resource, constant reflection on potential unintended consequences is essential: Whenever harmonization among the systems is taken to an extreme, it can easily lead to conformity of perspectives, thereby throwing the baby out with the bathwater.

As the authors will argue, in a truly international cooperation harmonization hardly can lead to such a consequence. It is for such a truly international project in which diversity adds value to the common enterprise that the attribute 'transnational' will be used. If this is the goal, this still does not answer the question how to get there and even less how to maintain that property over time.

In addressing this question, this paper relies on various and recurring experiences of all authors in developing, organizing and conducting transnational research projects in transdisciplinary research areas. Such research typically takes place in a variety of spaces, and - beyond the researcher's workplaces - at non-places in particular. In recent literature, the concept of learning spaces, despite lacking a common definition, has been fruitfully applied to a number of research areas. Still, it is this concept that shall be used to describe how mutual and collective learning can be facilitated within transnational research networks and projects, in which physical 
and virtual contributions of single researchers span a net of overlapping learning spaces created around a mutual research interest.

In discussing the topic from this perspective, the authors attempt to provide some evidence for how this concept, and according theoretical frameworks, can provide added value for the purpose of identifying and reflecting on challenges typically met and opportunities unexpectedly created in the attempt to make transnational and multi-professional collaboration work. Therefore, this paper will pay due attention to preconditions of building trust among the researchers; means to foster and to maintain their commitment to a research project; some key issues to consider when forming and expanding the network; the role and significance of communication, including ICT tools, and the delicate task of initiating norming processes in the research group.

This mission will start by introducing the concept of learning spaces, only to elaborate on the way it can be fruitfully adopted to research networks, particularly those that are transnational and transdisciplinary in their character. The authors then will consider some challenges typically met in real existing transnational and transdisciplinary research networks as they experienced them. After discussion, the final step will lead them to consider ways of overcoming barriers by inhabiting diverse places to work together - an approach that is guiding to finally draw some preliminary conclusions. Tuckman's (1965) group development model will serve as a guideline for exposing key issues to consider in each stage.

\section{Working places as learning spaces}

A search of the growing literature on learning spaces reveals that transnational and transdisciplinary research networks have so far escaped the attention of those scholars who have been adopting this particular perspective (Maslo \& Lunardon 2015). Furthermore, it becomes evident that the understanding of what exactly learning spaces are and how the concepts are constructed and used differs in the literature available (e.g. Kolb \& Kolb 2005; Solomon et al. 2006). To analyse learning processes and scholarly inquiry within transnational and transdisciplinary research networks, the authors propose the following definition:

Learning spaces are such spaces equipped with the property of generating, eliciting, stimulating, facilitating, fostering or enhancing learning. They are spaces we are sporadically visiting, constantly inhabiting and sometimes consciously searching for. In fact, they hardly ever can be simply found. They are no ready-mades; spaces specifically designed for that purpose remain rather the exception than the rule, and 
we are inclined to rather call such pre-established settings places. Learning spaces have to be actively shaped and constantly reshaped to elicit learning, if not created and reinvented at all.

It's the learning effect that counts, and the primary question is which properties of a particular environment, social or individual configurations are setting it in motion, maintaining it or leading to it. A further question is which dimensions and facets this learning is encompassing or extending to.

According to Kersh (2015) individual learning processes in, at and through work can be split into an individual, an organizational and a spatial dimension. The first dimension focuses on the role of the individual learner. The second refers to the opportunities and constraints provided by the institutional framework, while the third dimension relates to workplaces in their property of providing potential learning spaces to be shaped, utilized and put to work by their inhabitants. Research networks can be regarded as paradigmatic examples for such learning to take place.

This gets even more evident when the concept is broken down into further relevant facets: physical, virtual, affective, cognitive and social spaces. Depending on the people involved, their knowledge, skills, values and attitudes, the nature of their task, the tools they use and the working conditions, these particular facets will be overlapping to some extent.

Figure 1 illustrates the five facets of learning spaces that appear most relevant. The physical facet (bottom left) can be captured easiest: learners are located within specific surroundings. This facet is more concrete than the virtual facet placed on top, just as the affective facet (bottom right) - dealing with emotions and sensual experience - appears more concrete than the cognitive facet. The cognitive and the virtual facet both are more abstract. While the latter (top left) - with the learner immersed into virtual spaces - still can be located, the cognitive facet (top right) does not easily allow learners to sense or place the learning anywhere and anyhow.

However, the social facet (depicted as an overarching circle in the centre in Figure 1 is interwoven and indeed penetrates all of those aspects. It remains the principal feature that orients learners to their physical, affective, virtual and cognitive facets, necessitating participants to shape and adapt them in order to set learning in motion. As Berger and Luckmann famously put it, "[i]n order to maintain subjective reality effectively, the conversational apparatus must be continual and consistent.” (Berger \& Luckmann 1966: 174) 


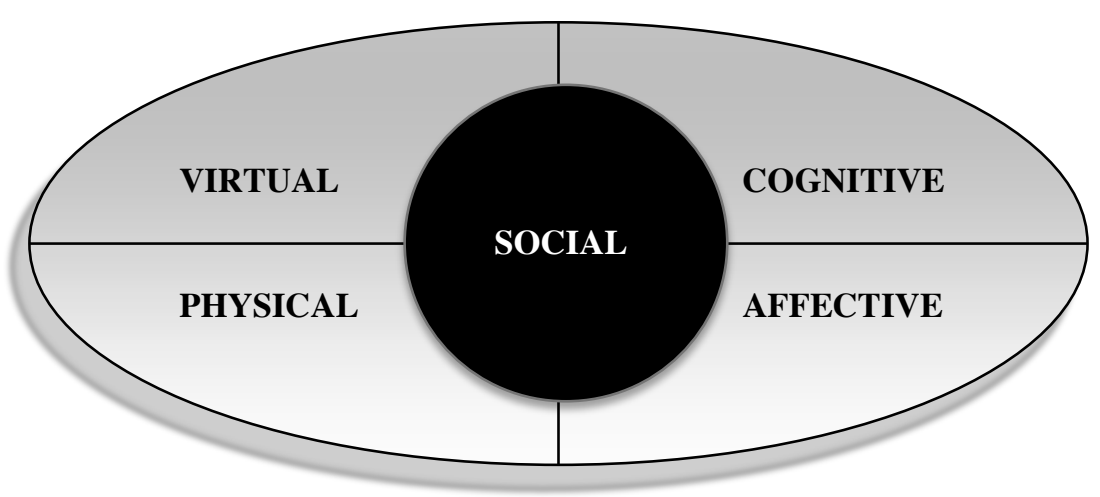

Figure 1: Five facets of learning spaces

In today's world, working environments are increasingly transcending their physical workplaces and institutional affiliations. Going along with global mobility, overlapping networks and the omnipresent connectedness, participants in transnational and transdisciplinary research missions are particularly dependent on more than just one workplace. Beyond that, in the research tradition on workplace learning, the term 'learning spaces' implies a shift from 'where' to 'how' learning is taking place, a shift that has preceded the adoption of that particular concept for quite a time.

To deepen the understanding on how transnational and transdisciplinary research networks work on the site and virtually and thereby move within the five facets of learning spaces, Tuckman's theory of group development, introduced in 1965, has been applied to the collected experiences of the authors. If essentially dealing with a social system, transnational and transdisciplinary research networks, just like any other groups, have to pass the stages forming, storming and norming in order to come up with real performance.

Forming: As insecurity prevails among the participants in this initial stage and relationships still need to be established, all eyes will be on the facilitator who is facing the expectation of directing the group to a common goal. Beyond orienting the participants towards the tasks to be addressed, s/he also should provide opportunities for participants to establish relationships with each other. 
Storming: After participants gained confidence, conflicts and polarisations will initiate the second stage of group development. Participants need to clarify and will start questioning presumably established relationships and task requirements.

Norming: As storming will necessary lead to some participants exceeding boundaries and breaking unwritten rules, an agreement has to be found on how to relate to each other, and what to avoid when doing so. Open exchange and acceptance characterise the third stage of group development. Participants openly share their views, jointly develop new standards and find agreements on the roles and functions everyone will assume - formally or informally - in the next stage to follow.

Performing: It is only after all of these predominant tasks are accomplished that a group can be expected to concentrate on its task, and is propelled to coordinated action which, along with the implementation of ideas, drives the fourth stage of group development. Participants rely on the structure agreed on and nothing prevents them from pursuing common goals.

Ultimately, this opens the way for expanding the learning spaces beyond shared physical places and can even extend to non-places when researchers on the move are using every place, which offers the right conditions to work no matter where they are. Therefore, non-places also have a considerable impact on the research process. Those morph into social, cognitive, affective, physical and virtual learning spaces and create a connection with the research network.

\section{Shaping working spaces}

Research groups are a common feature in the academic arena. Nevertheless, transdisciplinary and transnational research enterprises are rather the exception than the rule. In this particular case, researchers do not simply decide to work together to develop and conduct a common research project. Such research groups need time and resources to develop: Either researchers are well acquainted and wish to engage in joint efforts, or they meet each other at one occasion and decide to collaborate on a topic and eventually include some more researchers to accomplish their mission. In some cases, a loose network, designed to bring all resources together to start a new research project, already exists. It can be open, or not open at all, to welcome new members.

To initiate a research network, a physical learning space allowing members to meet face to face will mostly be needed, particularly at the beginning. Members will have to experience that they will be able to build on common ground. Therefore, the first challenge lies in attracting researchers with common or at least overlapping 
research interests, participants sharing methodological preferences or expecting to complement each other in terms of their expertise. Choosing the right channels to share individual and collective research work and to attract or inform key stakeholders in the network's area of interest will facilitate the members in their attempt to find common ground.

Within a transnational and transdisciplinary research network single researchers will need to get acquainted with a multicultural and - to some extent - multilingual working environment. Most likely they will have difficulties to find their place within a group consisting of researchers from various scientific communities. Considering these difficulties it is worthwhile to include people with a cosmopolitan attitude, who are open-minded and have interests beyond their own disciplines, research areas and expertise.

The dark side of this recruitment strategy is that it is likely to attract researchers who share the attitude of smelling opportunities. Such members will typically be quite busy, they might need to plan in the long term and sometimes find it difficult to stick to deadlines, whenever new opportunities are unexpectedly catching their attention.

Sometimes, it might therefore be preferable to use synergies by building a collaborative research group around existing networks who share similar cultures and practices. Nevertheless, success in the social dimension of transdisciplinary collaboration depends on the ability and willingness of members to relate to researchers belonging to different disciplines and research traditions, and to engage with them, constantly searching for mutual understanding (Bergmann et al. 2012: 45). Research groups are - and actually need to be - contested spaces, but glancing at Figure 1 - one can imagine that such contestation has to be lifted to the cognitive space. If it is merely affective, this will put the network in danger of losing its ground. A further obstacle for the research network to proceed is that some disciplines and research traditions are commonly considered more dominant than others. In a truly transnational enterprise, the informal power of individual members thus needs to be balanced.

After having mastered the challenge to find the right people to work with, both financial and time constraints often make it impossible to meet on a regular basis or even to plan face-to-face meetings at all. This is a serious obstacle; as such meetings can work miracles. They allow participants to 'smell' each other, to personally engage with colleagues on the site, not least in the informal setting - during coffee breaks, lunches and dinners - which virtually cannot be overestimated in terms of its capacity to sustainably shape the research network. Social activities prepare the ground for shaping affective learning spaces which allow its inhabitants to develop trust and start negotiating basic attitudes, which at best should be shared among all research network members over time. 
Only an atmosphere of trust allows researchers to fully engage in discussions and fully immerse and engage in cognitive learning spaces. As most of the challenges within the cognitive learning space root in self-perceptions, beliefs and understandings of every single researcher self-reflections might be encouraged within the group. Moreover, transdisciplinary exercises should be initiated, as those can transcend the boundaries of disciplinary learning spaces. To find common ground in a transnational and transdisciplinary research network is an intense and time consuming mission, as researchers mostly face the difficulty of having been socialised in particular research traditions. Communication is crucial also for working in a group with colleagues who hardly all share the same native language. For newcomers to transnational and transdisciplinary research networks it might be particularly challenging to develop a transnational attitude and a transdisciplinary tone. When addressing colleagues, misunderstandings of verbal as well as nonverbal communication acts might be rather the exception than the rule, and they might lead to considerable confusion. The challenge to work within different academic traditions and to open up for previously unknown concepts demands researchers to actively listen to each other and to keep their minds fresh and open. Therefore, an inviting environment (physical and/or virtual) where research and ideas can be openly shared and constructively discussed is a key ingredient for success in such contexts. If opportunities to relax and celebrate milestones which have been accomplished by the group can be provided occasionally, this certainly facilitates the group process.

A research network might also find it challenging to choose adequate ICT tools for different purposes, to build its virtual learning space and use it efficiently. Information flows need to be organized in a way that will be easily accessible to all (non-)members. To accomplish this task, it might help to draw on experiences of all members and to rely on those channels preferred and constantly used by various members, including social media platforms and messengers, such as Facebook, Research Gate, WhatsApp, Skype or Line to reach out to every member and to avoid having to wait for delayed responses.

Finally, special consideration should be given to the tasks and responsibilities of a facilitator. As good leadership is generally hard to find, and scholars rarely receive training in this regard, researchers are typically hesitating to take over that honourable and mostly unpaid duty with open hands on top of all other responsibilities they might have. Nevertheless, a research network needs good governance to sustain over time and to ensure its performance. To reckon the experiences of the authors, a research network should look out for a member who has previous experiences in leadership and voluntarily likes to take up the tasks and responsibility of a facilitator. A facilitator with skills to manage collaboratively might make the difference between success and failure in transdisciplinary efforts. 
S/he will be the one to direct the network to a common goal, to support the establishment of relationships within the network, to provide orientation to its members and propel the group towards agreed-upon action. To move on to the next stage of group development, such facilitator needs to provide an environment where members can succeed in forming a research network and can be assured of continuous actions. Meeting face-to-face in order to initiate this process and accomplish its task can be considered a precondition in order to take the next step of the group's development. A facilitator also needs to be aware that further meetings need to be scheduled when the network intends to expand, as the delicate task of including new members might draw the research group back to its initial stage.

\section{Being tempted by the tempest}

After the research network members have gained confidence they will - quite explicitly or rather implicitly - start questioning the established relationships and task requirements. The group has developed into its next stage: storming. Particularly in transnational and transdisciplinary research networks, in which the diversity among members is critical, such polarisation can easily lead members to retreat from the common mission. In this stage, members might defend their own disciplinary paradigms and advocate their own ideas, research topics and preferences within the network.

In this stage, finding a real-world problem to engage with is preferable to basing the group's work on theoretical assumptions. In transdisciplinary research, the primary obstacle comes from a lack of common problem focus (Young 2000). Without such a focus, researchers from different disciplines typically spent a lot of time discussing terminology, definitions and assumptions in the single disciplines without integrating them or including the perspectives of stakeholder outside academia. Enduring debates on different intellectual styles and cultures can create barriers for effectively working in a team.

The task the group is implicitly engaging with in the storming stage encompasses clarifying roles, functions and preferences, including potential contributions of every single member. It is therefore recommended to accept and give room to fights and arguments among the members and to listen carefully to the diverse inputs, including non-scientific stakeholders. While conceding room to such arguments, counter-arguments and debates, the facilitator should act as a model using simple and commonly understandable language, thereby inviting members in, encouraging them to openly share their views, including transparency within the differences and the option to agree to disagree on a number of issues within the group. Facilitators 
can, in and by their function, provide space for members to show their own potential and to prepare the way for proposing productive solutions to some of the issues discussed and viable strategies to proceed further as a group. Moreover, they can support arguments and proposals that help to balance informal power relations, to integrate different aims and needs and to undermine such rules or concepts that would limit or restrict the range of thoughts and ideas that could provide or inspire potential contributions to the network's mission, thereby keeping the door open for creativity to flow in and, at the same time, encouraging all members to step out of their own box.

As dealing with conflicts is not everyone's cup of tea, individual members will have difficult times coping with the tensions occurring. Therefore, the facilitator will have to actively engage in the group process. If social activities can be arranged, this will help to clarify relationships and reinforce trust among the members. After all, it can be quite challenging to stay open minded and innovative when being overwhelmed by the tempest. ICT tools might help to create distance and structure, but they also bear the danger of further escalation of conflicts. In this case, encouraging the participants to review emails, chat protocols or forum contributions to track potential misunderstandings, can facilitate the group to move on to the next stage.

\section{Finding the right bricks to build}

When the group moves to the next stage new challenges arise, necessitating participants to develop norms and standards for collaborative work.

As open and respectful exchange provides the ground for the joint development of such group norms, the research network can build on its established communication channels to find ways and provide examples of communicating with courtesy and respect. In the context of transnational and transdisciplinary work, special attention needs to be paid to balance the influence of single disciplines to initiate constructive and critical dialogue continuously within the research network. In his work for the UNESCO, Lattanzi (1998) pointed out that transdisciplinary knowledge could be understood as intellectual outer space. The transforming process of synthesis and partial alignment of ideas and perspectives are of key importance for transnational and transdisciplinary research. In a similar fashion, Pohl and Hadorn (2008: 112) argued that diversity of perception or perspectives should be addressed as a first step of mutual learning and integration for transdisciplinary research. This seems particularly promising as it allows the group to find forms of collaboration and means to integrate a whole set of such forms 
which will further on determine the structure and intensity of exchange among researchers and external stakeholders.

Facilitators can well propose some norms, but they need to set a good example when communicating in the group in the first place, encouraging participants to follow their example and carefully reflect basic principles of good communication. Furthermore, they can contribute to create an environment that facilitates an attitude of learning from each other, catch the interest of members by triggering a transition from mere meeting to collaboration. Meeting face-to-face is highly recommended in order to accomplish that task, as shared norms are essential for the group to proceed to its best performance: "the individual may resort to various techniques of realitymaintenance even in the absence of actual conversation, but the reality-generating potency of these techniques is greatly inferior to the face-to-face conversations they are designed to replicate. The longer these techniques are isolated from face-to-face confirmations, the less likely they will be to retain the accent of reality." (Berger \& Luckmann 1966: 174-175) For the work that is supposed to flow out of it in the next stage, norming can be considered the most intensive stage of group development.

Another challenge lies in the expectation to make joint decisions while ensuring participative decision finding and procedures. Active listening needs to assure that the diverse points of views, ideas, key arguments and counterarguments are simply ignored or lost and that they would at least appear in the records for further discussion. This will contribute to establishing a norm of mutual understanding, which will be the basis for constituting new structures. Nevertheless, this is all but a simple task to accomplish as problems of mutual understanding may arise from different research backgrounds. Therefore, enough time needs to be reserved to clearly frame and eventually reframe such problems.

One could start this process by constructing a competency profile within the group and propose appropriate research methods, which could allow participants to engage in research activities by building on common ground. Conducting qualitative and participatory research is particularly challenging, as it tends to expose different understandings, perspectives and approaches much more than quantitative research, along with conceptual and terminological issues. Accordingly, it relies much more on physical learning spaces where research network members can share, discuss and creatively develop their work.

A group also can start by stating a problem (which is preferable to a theory based on a single discipline) and to consider external stakeholders to check whether, among the participants, everyone can relate to a particular problem and those key actors having a stake on it. Identifying the right research question and negotiating conceptual backgrounds and appropriate research methods will appear quite challenging if the researchers are tight to one's own disciplinary and institutional context. In any case, mutual understanding will be key to accomplish the task at 
hand. It is a prerequisite for structured collaboration in which perspectives and competencies of all members need to be integrated.

Building trust and satisfaction within the research group will remain the main purpose of initiating norming. This will allow the participants to reach out to each other and to find a common mission, one bridging their individual disciplines and preferred research practices.

The establishment of a code of ethics supports the process of building mutual trust and understanding and at the same time provides guidance for the work within the group. It might include some principals on how to communicate within the network; how relevant information is shared among all members, which ICT tools are used, and how; how research will be conducted, research data will be shared, and findings distributed and discussed. In order to address potential worries about intellectual property, an agreement needs to be found on which guidelines to apply for authorship and ownership issues (including access to data-bases) within the network.

Moreover, an agreement on roles and functions of members should be initiated along with an agreement what good leadership implies and commitment means. There will always be times in which not everybody involved in the network will be able to engage in every single activity, or to catch up with particular deadlines, and times in which some members will engage in the delicate task of simulating activity. If this phenomenon spreads within the network, or such an attitude can be observed on different occasions, this issue needs to be addressed quite straightforwardly. At this point, it is preferable to meet and to start a norming process with the aim to develop a norm of honesty within the group. The insight that there will always be circumstances that make it difficult for individual members to engage on equal terms, or in all activities envisaged by the network, will facilitate that process. This is essential to avoid the free rider problem to arise, with the likely consequence of conflict and demotivation spreading among the network members.

What makes it easier to constructively address some of the problems mentioned in this section is if every member has a team to rely on at his home institution. Work and responsibilities can be shared among the team members, and they can engage in occasional discussion whenever questions are raised within the network. This would also help to assure continuity of those participating in the network as a whole, which is a key issue for all groups to make it to the performance stage. Combining physical and virtual learning spaces can further support continuity and allow those participants missing important occasions to catch up with the latest developments.

This shows that in order to make an impact as a research network, the researchers need to develop a new set of skills within the group. This will apply surfing - and shifting among - all facets of learning spaces. The group will be occupied with everything else than performance, immersed in affective space, until 
it agrees on basic standards and norms, which ultimately will open the way to performance. But one also needs to be aware that the group can fall back at any point, storming to clarify the positions of everyone involved, and the norming game will have to start over again when particular circumstances or issues that will be raised at that point will be demanding additional or more specific norms to be negotiated within the group.

\section{Inhabiting diverse places to work together}

Having managed to overcome the challenges of forming, storming and norming the researchers will be enabled to make use of their full potentials by inhabiting diverse places to work together. When this can be observed, it is indicating that the group has been moving to the performance stage.

Still, a number of constraints will keep the research network from straightforwardly addressing the agreed-upon tasks. Members will have to put a lot of efforts into their collaborative work to stay energized from the launch of the research project throughout the distribution of the research findings. The more intensive collaboration will get, the more the social, cognitive, affective, physical and virtual learning spaces will overlap and align. Affective learning spaces will pop up regularly throughout the research process, as researchers have to deal with stress, exhaustion, misconceptions, but also with moments of joy and satisfaction.

Thus a challenge lies in a well-structured and easy flowing communication, which is not only complex, if colleagues sit in their offices on different continents, but also, if they sit next doors. A lack of good communication closes down every research project no matter of its originality and greatness. Therefore, a lot of energy needs to be spent on keeping the conversation going and continuing to build ownership in terms of the group process and contents.

The ICT tools introduced and established within the network can support the continuing conversation. It will sometimes be enough to drop a small note via a messenger to bring an issue to the attention of other members. It still might be difficult to fine-tune the amount of messages not risking to lose the interest of others. In any case, an overload of emails should be avoided. If this is not possible, key words in the heading could be agreed upon to indicate the purpose or the expectations (e.g. to do, update, research materials, for discussion, urgent reply etc.) an email carries for the readers. More generally, the group has to find ways to choose communication channels wisely, which is highly depending on the purpose and the task to be accomplished. Sometimes it also might be fruitful to arrange a face-to-face or an online meeting and discuss the next steps to take there. Nevertheless, arranging an online meeting while working in different time zones can be challenging too. Normal working hours easily extend into early mornings and late 
nights. However, if the time difference is well-managed, it can also be of good use, particularly when a deadline is approaching and researchers can work in day shifts sending a document back and forth without missing out one single night.

In the performing stage, members will take the responsibility for work packages and dedicate time slots to accomplish those. Again, these need to be fine-tuned in the group and clearly communicated. Freedom, along with time and financial resources provided by the home institution to travel to meetings and conferences would facilitate full engagement in the research process. As the lack of financial and time resources makes it almost impossible to create and sustain a transnational and transdisciplinary research network and to conduct joint research, one of the hardest challenges mostly lies in securing funding for research projects and meetings.

As most researchers have full agendas and an endless list of tasks, necessitating them to balance their research activities, teaching and administrative duties at their workplace and beyond, to successfully sustain over a longer period transnational and transdisciplinary research networks equally need to rely on local support - and consider ways of mobilizing such resources (e.g. by including colleagues and students) to share workloads, back each other up, develop ideas and strategies further. The value of having such a team on the spot cannot virtually be overestimated, as it also holds a potential solution to the lack of acknowledgement one typically gets within one's institution, by broadening one's alliances.

In the performing stage facilitators hardly can lean back. Most importantly, they should concentrate on the delicate task of managing diversity among the members, making sure the tasks and responsibility are collectively shared, rewarding individual members, teams or subgroups within the network for their valuable inputs and strong commitment, monitoring outcomes corresponding with the established norms, paying attention to the agreed timeline and the delivery of work packages, of organizing celebratory events, when the research network has achieved its goals or significant milestones, and of making sure activities and outputs are visible to all members as well as external audiences and stakeholders.

As there are only a few journals that provide a forum for transnational and transdisciplinary research, the distribution of research findings brings the next challenge, one in which the facilitator again will have to shoulder some responsibilities. The performance indicators by which academic contributions are commonly rated within scientific communities tend to speak the language of single disciplines, so that the voices whispering at the boundaries and intersections of established (common) places hardly can be heard. Moreover, a potential problem for projects transcending national boundaries arises from the fact that particular journals might hold a different place, or no place at all, in the national rankings on which researcher's performance is measured in the single member's countries. 
These constraints need to be taken into account when a publication strategy for the work and outcomes of a transnational and transdisciplinary research network is considered, as it remains essential for its members to share their insights and achievements, to make their work visible and attract potential funding or new members, keeping in mind the latter might bring the research network back to the initial stage.

\section{Conclusion}

Although the 'spatial turn' in social sciences and humanities can be dated back to the 1980 s, the concept only recently got vibrant in educational sciences. Looking closer into our field of inquiry, higher education and research in education and learning, the value of space as a dimension to go beyond the localisation related to place has been recognised. The present contribution tried to show how this idea can be fruitfully applied to a context which has not yet been considered in the growing literature on 'learning spaces': transnational and transdisciplinary research networks.

This paper argues that learning takes place at the intersection of the facets of learning spaces depicted in Figure 1. One conclusion, which tentatively can be drawn from the observations, is that one most likely finds a network at the best of its performance where virtual and physical spaces overlap, and whenever affective and cognitive learning spaces merge, with all of those facets converging towards the social space, which is linking them. In all earlier stages of group development, single contributions - however cognitive they might be in terms of the intention of the contributors - hardly can avoid affective connotations and consequences, and the group will be highly dependent on physical places in order to proceed.

The main task - and indeed the main challenge - of such research networks is to keep the conversation going. As Berger and Luckmann put it, "the conversational apparatus must be continual and consistent." (Berger \& Luckmann 1966: 174). The central role ascribed to communication flows can be easily reworded in the language of systems theory, e.g. by relying on the way social system are defined and conceptualized by Niklas Luhmann (1984), with communication acts succeeding each other. Similarly, the social facet of learning spaces essentially consists of communication, generating all kinds of consequences in the psychological arena of those who are linked into, connected by, and finally interconnected through those communication flows: "Generally speaking, the conversational apparatus maintains reality by 'talking through' various elements of experience and allocating them a definite place in the real world." (Berger \& Luckmann 1966: 173)

A further task consists in channelling the energy of (at least some of) its individual members towards the common research interest and to propel it to 
achieve common goals. This, of course, implies to pay particular attention to group dynamics. It also brings the role of the facilitator into the picture, a role that is essentially encompassing the delicate task to manage diversity, by maximising its potential impact and mitigating potential obstacles. To support group development, a facilitator not only needs to balance the stakes and contributions of individual members, s/he also has continuously to keep the balance within the group as a whole. Initially, s/he will have to take over most functions a group needs in order to proceed, while when other members assume a function s/he will have to step back, to give room for others to fulfil tasks and assume roles s/he formerly had taken on by $\mathrm{him} /$ herself.

A research group is expected to gain independence of spaces to the extent that it 'prefers' to continue to concentrate on storming or it reached the peak of its performance - which does not mean that it couldn't fall back to previous stages, for instance when a network is expanding its membership. Meeting physically, face to face, and in an appropriate setting thus resulted to be particularly important in two stages of group development: when forming the group, and in the norming stage, which is the one proceeding real performance.

Storming also can take place in virtual spaces and indeed is even likely to happen naturally once such spaces are inhabited by the participants of a research group. This is somehow building pressure to meet. When no face-to-face meetings follow for a long time, this will make norming an even much more difficult only task to accomplish and one which is even more unlikely to be achieved in virtual spaces only. And norming continues to be a crucial step to take in order to come up with a network's real performance and to realize its full potentials. Once a research group made it to the performing stage, physical places and meetings are somehow losing their relevance. A network will work independently, gain autonomy in terms of times and modes of collaboration.

Cyberspace can be considered a non-place, a place with almost no limits where one easily gets lost. In the performing stage, it still can be used to advance learning. Since its introduction, dating back to 1989, the World Wide Web has indeed provided powerful means to reshape the research world and to transform - and develop new models of - learning and conducting research. The research society has been affected in terms of collaboration, participation, communication, intellectual property, content, and information. Researcher's workplaces have been expanded into the virtual space. The digital devices are advancing day-by-day and support researchers when transforming their workplaces into learning spaces. Particularly transnational and transdisciplinary researchers are increasingly utilizing these tools to develop their work further. Learning in, at and through work is no longer tied to a specific place but can - and increasingly will - happen on the move. 
Other non-places such as hotels, airports, train stations and shopping centres become relevant when working in a transnational and transdisciplinary research network as the researchers smartphone, tablet and/or laptop is carried around and used by them whenever they find a place suitable enough to work, albeit it is only standing in the line waiting to board the aircraft while reading and answering emails. Thus, such (non-)places need be considered when analysing the 'how' of learning in, at and through work. Referring to Marc Augé (1995) non-places are distinguished by the notion of passing by, lingering over and consuming without developing any social or emotional bond with people and/or places. This bears more than a casual assemblance with what Granovetter (1973) famously coined "the strength of weak ties". We even would claim that it is expanding his account - from the social world (real people) to a much more manifold environment, which is incorporating physical, cognitive, emotional and motivational properties - much in the fashion of Bruno Latour's (2005) theory. Therefore, such places are welcoming guests, passengers, shoppers etc. with the promise to reduce emptiness, to speed up waiting times and to set minds and souls in motion. Moreover, not missing out on rewarding all kinds of (re-)searchers by proven their assumption might be right: empty places can - as they are empty - be filled with everything, not least creative ideas and ground-breaking thoughts. 


\section{References}

Augé, M. (1995). Non-places. Introduction to an Anthropology of Supermodernity. London, NY: Verso.

Berger, P. L. \& Luckmann, T. (1966). The Social Construction of Reality. A Treatise in the Sociology of Knowledge. Garden City, NY: Anchor Books.

Bergmann, M., et al. (2012). Methods for Transdisciplinary Research: A Primer for Practice. Frankfurt a. M.: Campus.

Egron-Polak, E. \& Hudson, R. (2014). Internationalization of Higher Education: Growing expectations, fundamental values. IAU 4th Global Survey: Executive Summary. Retrieved from: http://www.iau-aiu.net/sites/all/files/IAU-4thGLOBAL-SURVEY-EXECUTIVE-SUMMARY.pdf [accessed 15.07.2016].

Granovetter, M. S. (1973). The Strength of Weak Ties. American Journal of Sociology, 78(6), 1360-1380.

Gray, B. (2008). Enhancing Transdisciplinary Research Through Collaborative Leadership. American Journal of Preventive Medicine, 25(2), 124-132.

Kersh, N. (2015). Rethinking the learning space at work and beyond: The achievement of agency across the boundaries of work-related spaces and environments. International Review of Education, 61, 835-851.

Kolb, A. Y. \& Kolb, D. A. (2005). Learning Styles and Learning Spaces: Enhancing Experiential Learning in Higher Education. Academy of Management Learning \& Education, 4(2), 193-212.

Latour, B. (2005). Reassembling the social: an introduction to actor-networktheory. Oxford New York: Oxford University Press.

Lattanzi, M. (1998). Transdisciplinarity at UNESCO. Retrieved from: http://unesdoc.unesco.org/images/0011/001146/114694eo.pdf [accessed 20.10.2016].

Luhmann, N. (1984). Soziale Systeme. Grundriß einer allgemeinen Theorie. Frankfurt am Main: Suhrkamp.

Maslo, E. \& Lunardon, K. (eds.) (2015). Annotated Bibliography. Working places as learning spaces: contextualising lifelong learning in Asia and Europe. Retrieved from

http://asemlllhub.org/fileadmin/www.asem.au.dk/publications/RN2_Annotated Bibliography_first_edition_08-10-2015.pdf [accessed 21.10.2016].

Nicolopoulou, K., Koštomaj, M. \& Campos, A. (2006). How to address group dynamics in virtual worlds. AI \& Society, 20(3), 351-371.

Pohl, C. \& Hirsch Hadorn, G. (2008). Methodological challenges of transdisciplinary research. Natures Sciences Societies, 16, 111-121.

Solomon, N., Bound, D. \& Rooney, D. (2006). The in-between: exposing everyday learning at work. International Journal of Lifelong Education, 25(1), 3-13. 
Sommerville, M. A. \& Rapport, D. J. (eds.) (2002). Transdisciplinarity: recreating integrated knowledge. Montreal QC: McGill-Queens University Press.

The Higher Education Academy (2014). Internationalising Higher Education Framework.

Retrieved from: https://www.heacademy.ac.uk/sites/default/files/resources/internationalisinghefr ameworkfinal.pdf [accessed 15.07.2016].

Tuckman, B. W. (1965). Developmental sequence in small groups. Psychological Bulletin, 63(6), 384-399.

Young, K. (2000). What makes transdisciplinarity succeed or fail? Second report, pp. 218-220. In Somerville M. A. \& Rapport D. J. (eds.) Transdisciplinarity: recreating integrated knowledge. Oxford, UK: EOLSS Publishers Ltd 